\title{
Research on Disturbance of LED display of Large Urban Intersection Zone on Driver's Vision Based on Subjective Questionnaire
}

\author{
Rui Dang, Lan Wang ${ }^{1}$, Lixiong Wang, Tingting Yu \\ Tianjin University \\ Tianjin Key Laboratory of Architectural Physics and Environmental Technology \\ Tianjin China \\ Corresponding Author: Lan Wang E-mail: lglgmike@163.com
}

\begin{abstract}
With the continuous development of city construction process, a new type of media advertisement carrier (outdoor LED display) appears more and more in the city. It has many advantages that different from the traditional media, such as large area, bright color, dynamic change, high brightness, strong visual impact and so on. And along with the more mature technology and the lower cost, outdoor LED display gets more and more favor of people. But many problems are exposed gradually.
\end{abstract}

Keywords-City intersection, Outdoor LED display, Visual disturbance

\section{INTRODUCTION}

With city's construction in progress, outdoor LED screens are widely used in downtown, commercial center, leisure pedestrianized streets, city parking lots, near transport hubs, railway, subway and other traffic guidance systems. While, as to some large LED screens set in traffic sensitive areas like city's intersection areas, its high brightness and switching frequency causes visual disturbance to passing pedestrians and vehicle, causing visual pollution; its dynamic flicker, color conversion is easy to distracted driver's attention, causing car accidents and a series of accidents, resulting in road traffic safety problems. This article is aimed to explore the nighttime outdoor LED large screen's visual impact on drivers and to put forward the main impact to provide direction for improvement.

\section{DRIVER'S SUBJECTIVE FEELINGS TOWARDS LED LARGE SCREEN BRIGHTNESS AND DYNAMIC FLASHING}

Through the subjective collate questionnaire analysis, we found the drivers have different subjective feelings of the Tianjin urban road intersection zone's six dynamic flashing LED display brightness, the specific circumstances in Table 1.

Take the absolute value of driver's subjective evaluation on the LED large screen brightness dazzling degree and dynamic flicker value, get relationship curves obtained mean brightness and large LED screens. As Figure 1 Figure 2:

From the above table it can be seen broadly, LED large screen average brightness level is higher and for the dynamic flashing LED large display, as it involves more factors, the screen flashes the number of times, change of the color, change of the screen composition, the picture transform interval time, and so will be on the driver's subjective perception of impact, here are lists the maximum instantaneous of each screen's brightness values, generally it can be seen that the higher instantaneous change of brightness in value, the worse the driver's visual experience will be.

TABLE I. DRIVERS' MEAN SUBJECTIVE EVALUATION OF LARGE LED SCREENS BRIGHTNESS

\begin{tabular}{|c|c|c|c|c|c|}
\hline number & Carrier building & $\begin{array}{l}\text { Mean LED screen } \\
\text { brightness }\left(\mathrm{cd} / \mathrm{m}^{2}\right)\end{array}$ & $\begin{array}{c}\text { drivers' mean } \\
\text { subjective } \\
\text { evaluation }\end{array}$ & $\begin{array}{l}\text { LED screen brightness } \\
\text { value of the maximum } \\
\text { instantaneous }\left(\mathrm{cd} / \mathrm{m}^{2}\right)\end{array}$ & $\begin{array}{c}\text { drivers' mean } \\
\text { subjective } \\
\text { evaluation }\end{array}$ \\
\hline 1 & Tianjin Jin Bin International Hotel & 659.9 & -1.47 & 909.2 & -1.25 \\
\hline 2 & Tianjin, China Pacific Insurance Company & 183.6 & -0.09 & 320.9 & -0.16 \\
\hline 3 & Tianjin Bank of Jinzhou & 814.2 & -1.81 & 1982.1 & -1.09 \\
\hline 4 & Tianjin Yaohua in school discipline & 1737.5 & -1.53 & 3218 & -1.03 \\
\hline 5 & Tianjin Haowai mall & 160.8 & -0.25 & 634.79 & -0.5 \\
\hline 6 & Tianjin Isetan shopping malls & 84.6 & -0.19 & 466.5 & -0.28 \\
\hline
\end{tabular}




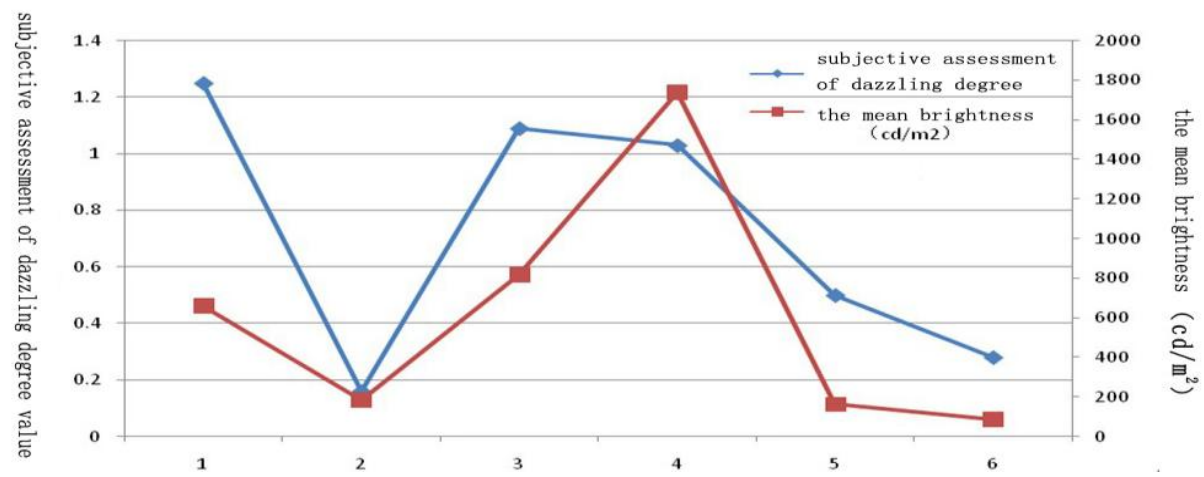

Figure 1. Relationship curve obtained subjective assessment of dazzling degree value and the mean brightness

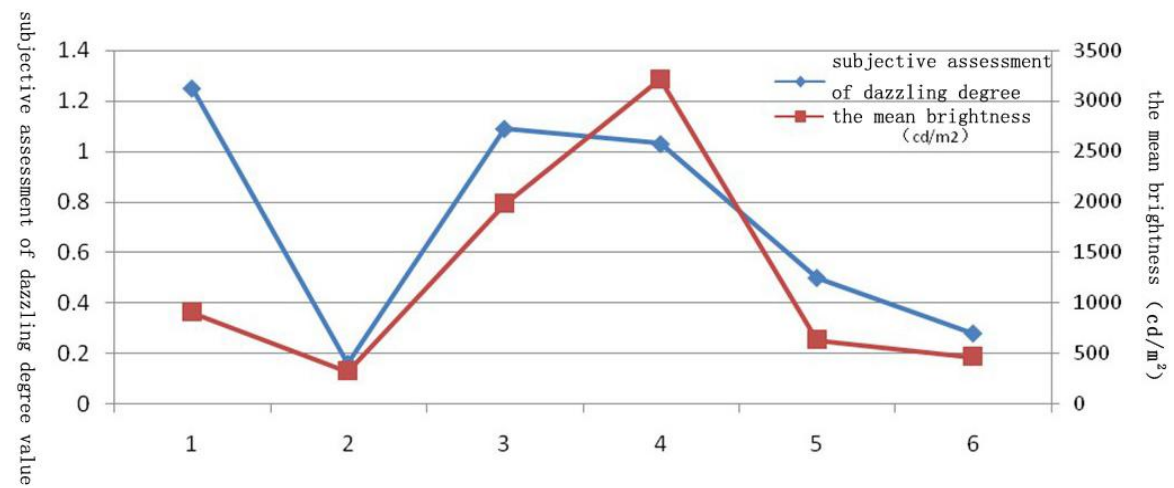

Figure 2. Relationship curve obtained the subjective assessment value of instantaneous brightness change and the mean brightness

\section{DRIVER'S SUBJECTIVE FEELINGS TOWARDS LED LARGE SCREEN DYNAMIC FLASHING}

The physical parameters linked with the subjective response by generally used questionnaires to assess the scale and magnitude in visual environment studies. Single factors and complex problems can get some results. But for some slightly more complex topics, it will useless. So the most commonly used method for semantic differential scales. [1] Based on the feedback questionnaire summarizing the information by SPSS software, large LED screen brightness, dynamic flashing and the driver's identification behavior, distraction, etc. correlation analysis are shown in Table 2 below: (Jin Bin International Hotel as an example)

TABLE II. ANALYSIS RELEVANCE PEARSON CORRELATION

\begin{tabular}{|c|c|c|c|c|c|c|}
\hline \multicolumn{2}{|c|}{} & $\begin{array}{c}\text { Degree of } \\
\text { recognition of road } \\
\text { barriers }\end{array}$ & $\begin{array}{c}\text { Driving } \\
\text { attention } \\
\text { dispersion }\end{array}$ & $\begin{array}{c}\text { Attention dispersion } \\
\text { waiting for traffic } \\
\text { lights }\end{array}$ & $\begin{array}{c}\text { Degree of } \\
\text { recognition on the } \\
\text { traffic lights }\end{array}$ & $\begin{array}{c}\text { Degree of } \\
\text { recognition for } \\
\text { pedestrians }\end{array}$ \\
\hline $\begin{array}{c}\text { Glare of LED screen } \\
\text { brightness level }\end{array}$ & $\begin{array}{c}\text { Pearson } \\
\text { Correlation }\end{array}$ & $.480^{* *}$ & $.554^{* *}$ & $.466^{* *}$ & .027 & .1 \\
\hline $\begin{array}{c}\text { Dynamic LED screen } \\
\text { flashes acceptance }\end{array}$ & $\begin{array}{c}\text { Pearson } \\
\text { Correlation }\end{array}$ & $.505^{* *}$ & $.595^{* *}$ & .303 & .062 & $.491^{* *}$ \\
\hline
\end{tabular}

Generally speaking, the correlation coefficient of the sample is showed by $r$, the collectivity is showed by p. For different types of variables, calculation formulas are different. In the correlation analysis, Pearson simple correlation coefficient is commonly used to calculate distance continuous variables. The application of Pearson simple correlation coefficient is wide. It has the following properties:
$|\mathrm{r}|<0.3$ Weak correlation
$0.3<|\mathrm{r}|<0.5$ Low correlation

\section{$0.5<|\mathrm{r}|<0.8 \longrightarrow$ Significant correlation}

$0.8<|\mathrm{r}|<1 —$ High correlation

Synthesize forms above, we can see that the correlation coefficient between the dazzling degree of all LED large screens studied and the degree of driver's attention dispersion is in the range of $0.5-0.8$, proving that there is a significant correlation between them. Every large screen has a certain influence on the driver's driving behavior.

Take objective data of each measuring point and subjective questionnaire data to analyze the average (Table 3). 
TABLE III. CORRELATION OF GLARE OF LED SCREEN BRIGHTNESS LEVEL AND DYNAMIC FLASHING AND DRIVER'S RECOGNITION DEGREE AND ATTENTION DISPERSION

\begin{tabular}{|c|c|c|c|c|c|}
\hline & $\begin{array}{c}\text { Degree of } \\
\text { recognition of } \\
\text { road barriers }\end{array}$ & $\begin{array}{c}\text { Driving } \\
\text { attention } \\
\text { dispersion }\end{array}$ & $\begin{array}{c}\text { Attention } \\
\text { dispersion waiting } \\
\text { for traffic lights }\end{array}$ & $\begin{array}{c}\text { Degree of } \\
\text { recognition on the } \\
\text { traffic lights }\end{array}$ & $\begin{array}{c}\text { Degree of recognition for } \\
\text { pedestrians }\end{array}$ \\
\hline $\begin{array}{c}\text { Glare of LED screen } \\
\text { brightness level }\end{array}$ & $\begin{array}{c}\text { Significant } \\
\text { correlation }\end{array}$ & $\begin{array}{c}\text { Significant } \\
\text { correlation }\end{array}$ & $\begin{array}{c}\text { Significant } \\
\text { correlation }\end{array}$ & Weakly correlated & Weakly correlated \\
\hline $\begin{array}{c}\text { Dynamic LED screen } \\
\text { flashes acceptance }\end{array}$ & $\begin{array}{c}\text { Significant } \\
\text { correlation }\end{array}$ & $\begin{array}{c}\text { Significant } \\
\text { correlation }\end{array}$ & Low correlation & Weakly correlated & Significant correlation \\
\hline
\end{tabular}

From the above analysis we can see that there are some interference of outdoor LED large screen's high-brightness and dynamic flashing to the driver's driving behavior, especially in the course of the driver driving distraction and danger to road barriers in terms of recognition, while the LED display for the driver identification pedestrians, traffic lights and other aspects of a weak correlation.

\section{CONCLUSION}

In this paper, we did research, selected the Tianjin urban road intersections, and conducted data measurement of brightness of the LED large screen and data analysis summarizing. We did in-depth analysis of outdoor LED large display their high brightness, dynamic changes and other physical features. At the same time, focusing on large-scale urban intersection zone's LED screen and the effect on drivers visually and driver's driving behavior on the interference, to provide a basis of a more scientific and reasonable setting of large LED screens.

\section{ACKNOWLEDGMENT}

This article is supported by a program of Tianjin Natural Science Foundation-The research of LED road lighting effect and energy saving in photopic vision mesopic vision, the item No. 10JCYBJC03800

This article is supported by a program of Tianjin Natural Science Foundation-Quantitative Research of LED Effected Exhibits Base on Protected Historical Relics, the item No.13JCQNJC07600

\section{REFERENCES}

[1] SPSS statistical analysis and practical, Liren Hao, Fan Yuan, Zheou Hao eds, China Water Power Press, 2003.1 